\title{
Direct Insight into the Reactivity of Pt Nanoparticles in CO Oxidation by Operando TEM and the Impact of Electron Dose Rate on Their Coarsening
}

\author{
Milivoj Plodinec, Hannah Nerl, Robert Schlögl and Thomas Lunkenbein \\ Fritz-Haber Institute of the Max-Planck Society, Berlin, Berlin, Germany
}

In general, heterogeneous catalysts are metastable materials that adapt to the chemical potential of the environment.[1] The in situ formed phases fluctuate locally and are often only stable under working conditions. Recent developments in operando transmission electron microscopy (TEM) techniques allow to study catalysts in their working environment and to visualize on the local scale these in situ generated structures. However, the applied electron dose rates needed to pinpoint these changes in different gas environments, in particular for high resolution imaging, could have a significant impact on the final observations. [2, 3]

In this study, we will show the influence of different morphologies and sizes of Pt nanoparticles (NPs) on their performances in the oxidation of $\mathrm{CO}$ (Figure 1) and unravel the response of Pt NPs in different gaseous environments, such as $\mathrm{CO}, \mathrm{O}_{2}$ and gas mixtures of $\left(\mathrm{CO}: \mathrm{O}_{2}: \mathrm{He}=1: 5: 19\right.$, Figure 2) to different electron beam dose rates. The investigated Pt NPs were prepared either in situ by the thermal decomposition of tetraamineplatinum(II) nitrate at $400^{\circ} \mathrm{C}$ (Figure 1a, method 1)[4-6] or ex situ by sputtering the Pt NPs directly on the microelectromechanical systems (MEMS) chip (Figure 1b, Figure 2, method 2). The experiments were conducted on an image aberration-corrected FEI Titan (scanning) transmission electron microscope (S)TEM operated at $300 \mathrm{kV}$ connected with a homebuilt gas feed and analysis system using commercially available gas-cell TEM holders.[4]

Using this operando TEM approach we were able to compare conversion rates in CO oxidation reaction of two differently prepared Pt catalysts. Pt NPs prepared by method 1 were found to have a very broad size distribution and irregular shapes (Figure 1a), while the ones prepared by method 2 exhibited more spherical shapes with rather uniform and narrow size distribution over the entire area (Figure 1b). Pt NPs prepared by method 2 were found to be more active and reach full conversion at $400^{\circ} \mathrm{C}$ (Figure 1c) compared to Pt NPs prepared by method 1 where a maximum conversion of $63 \%$ was achieved (Figure 1d). The ignition point seems to be almost independent of the method of preparation and was found at temperatures of $382^{\circ} \mathrm{C}$ (Figure 1c) and $392^{\circ} \mathrm{C}$ (Figure 1d), respectively. The difference of $10^{\circ} \mathrm{C}$ is probably caused by the error in the temperature measurements between two different MEMS chips. Subsequent high angle annular dark-field (HAADF) STEM imaging was conducted to study influence of the electron beam dose rates on Pt NPs prepared by method 2 at $400^{\circ} \mathrm{C}$ in the pressure range between 700 and 1000 mbar. The results show that Pt NPs prepared by method 2 are most stable in a pure oxygen environment (Figure 2a-c). This is evidenced by the much higher dose rate that causes changes in the NPs perimeter and density, compared to environments consisting of pure $\mathrm{CO}$ (Figure 2d-f) or gas mixture of $\mathrm{CO}, \mathrm{O}_{2}$ and He (Figure 2g-i). Note, that for relevant CO oxidation reaction conditions the perimeter of Pt NPs was stable for the first $1 \mathrm{~h}$ of observation under the electron beam dose rates as high as $450 \mathrm{e} / \AA^{2} \mathrm{~s}$.

In summary, the size and shape of Pt NPs were found to be essential for the conversion in MEMS based nanoreactors, but leave the ignition point almost unaffected. Furthermore, the influence of the electron beam has significant impact on the observations and depends on the gas environment and the applied electron dose rates. Thus, to reduce the influence of the electron beam to a negligible minimum, and to 
extract reliable information, systematic studies on influence of the total electron dose and dose rates for different environmental conditions are required.
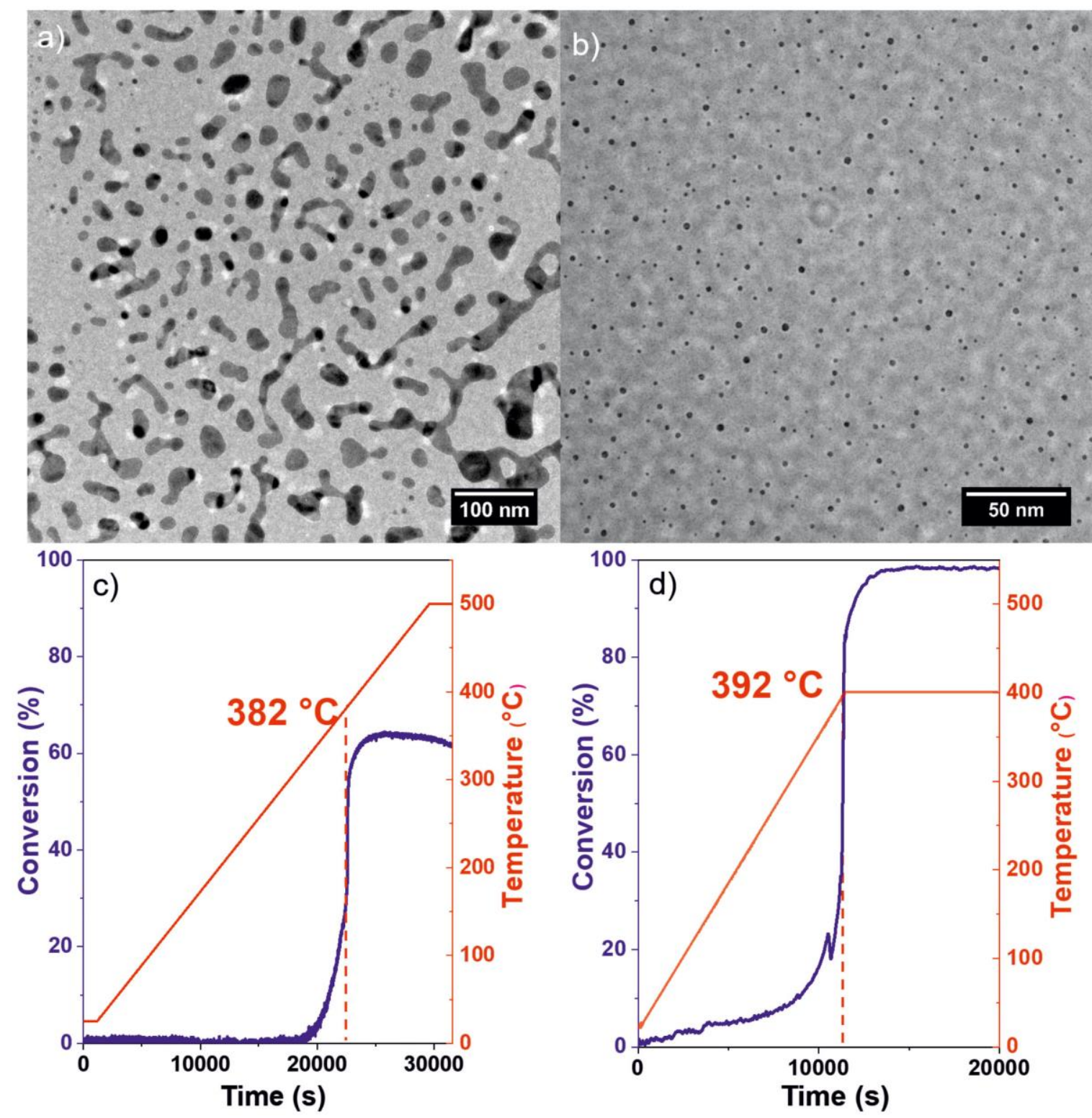

Figure 1. CO conversion of differently prepared Pt NPs investigated by operando TEM. a) Pt NPs prepared in situ by thermal decomposition in synthetic air $\left(20 \%\right.$ O2 in Helium) at $400{ }^{\circ} \mathrm{C}$. b) Pt NPs prepared by sputtering method with a uniform size $(\approx 2.3 \mathrm{~nm})$, shape and density over the entire MEMS chip. c) and d) Corresponding CO conversion graphs of Pt NPs shown in a) and b), respectively. Reaction conditions (temperature ramp: $1{ }^{\circ} \mathrm{C} / \mathrm{min}$ in a) and c), and $2{ }^{\circ} \mathrm{C} / \mathrm{min}$ in b) and d); pressure: $700 \mathrm{mbar}$; flow rate: $20 \mu \mathrm{L} / \mathrm{min}$ and gas feed: $\mathrm{CO}: \mathrm{O} 2: \mathrm{He}=1: 5: 19)$. 

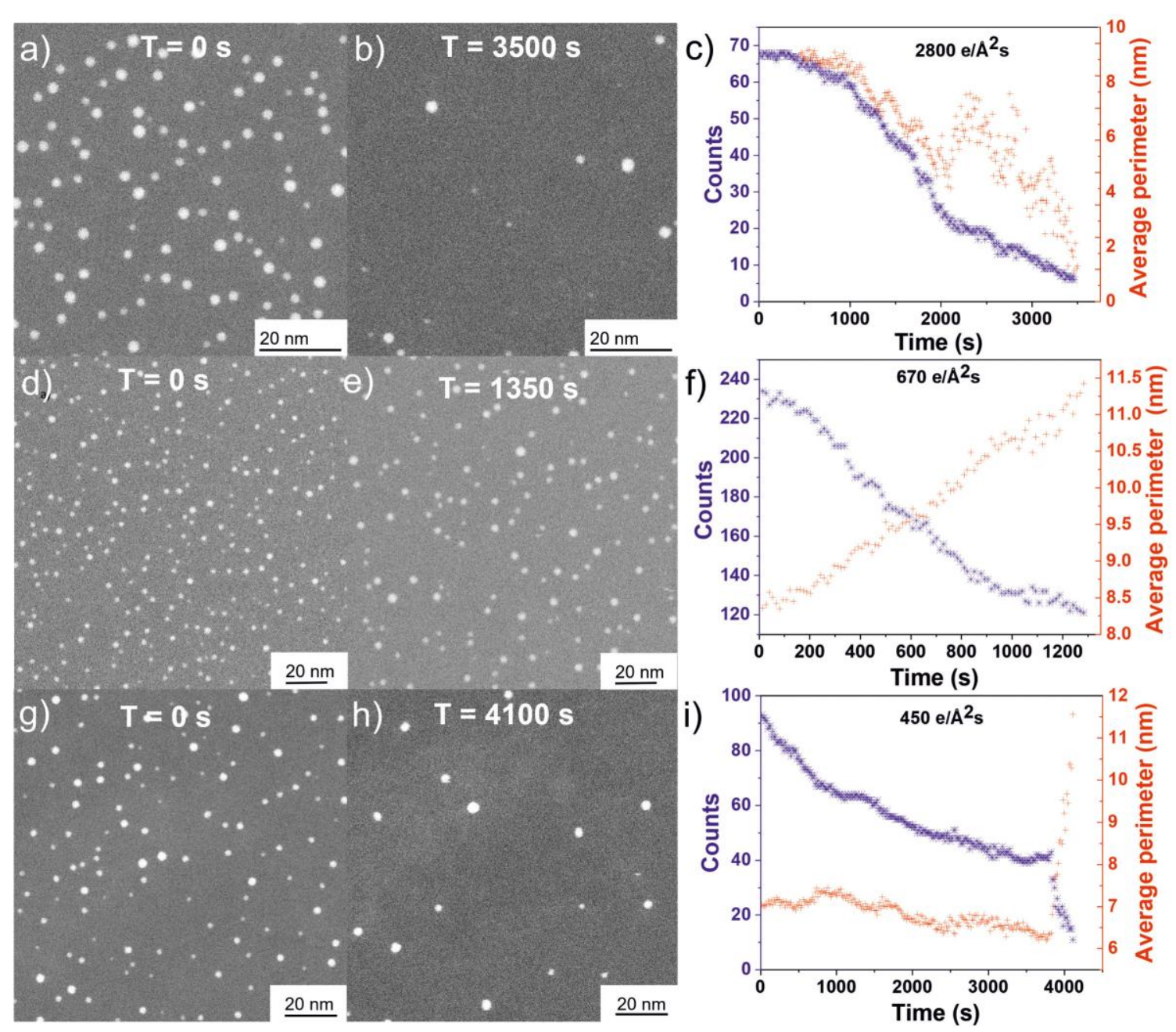

Figure 2. Influence of the electron beam dose rate on Pt NPs prepared by sputtering in different gas environments at $400{ }^{\circ} \mathrm{C}$. This figure shows HAADF STEM images of Pt NPs before and after continuous exposure to the electron beam, corresponding number of particles (counts) and average perimeter distributions of NPs: a), b) and c) for the $\mathrm{O} 2$ atmosphere at pressure of 1 bar; d), e) and f) for the $\mathrm{CO}$ atmosphere at 1 bar pressure; $\mathrm{g}$ ), h) and i) for the gas feed: $\mathrm{CO}: \mathrm{O} 2: \mathrm{He}=1: 5: 19$, during the maximum $\mathrm{CO}$ conversion (see Figure 1d) at pressure of 700 mbar.

\section{References}

1. Kalz, K.F., et al., Future Challenges in Heterogeneous Catalysis: Understanding Catalysts under Dynamic Reaction Conditions. ChemCatChem, 2017. 9(1): p. 17-29.

2. Behafarid, F., et al., An in situ transmission electron microscopy study of sintering and redispersion phenomena over size-selected metal nanoparticles: environmental effects. Physical Chemistry Chemical Physics, 2014. 16(34): p. 18176-18184.

3. Simonsen, S.B., et al., Direct Observations of Oxygen-induced Platinum Nanoparticle Ripening Studied by In Situ TEM. Journal of the American Chemical Society, 2010. 132(23): p. 7968-7975.

4. Plodinec, M., et al., Versatile Homebuilt Gas Feed and Analysis System for Operando TEM of Catalysts at Work. Microscopy and Microanalysis, 2020.

5. Plodinec, M., et al., Insights into Chemical Dynamics and Their Impact on the Reactivity of Pt Nanoparticles during CO Oxidation by Operando TEM. ACS Catalysis, 2020: p. 3183-3193. 
6. Vendelbo, S.B., et al., Visualization of oscillatory behaviour of Pt nanoparticles catalysing CO oxidation. Nature Materials, 2014. 13: p. 884-890. 